
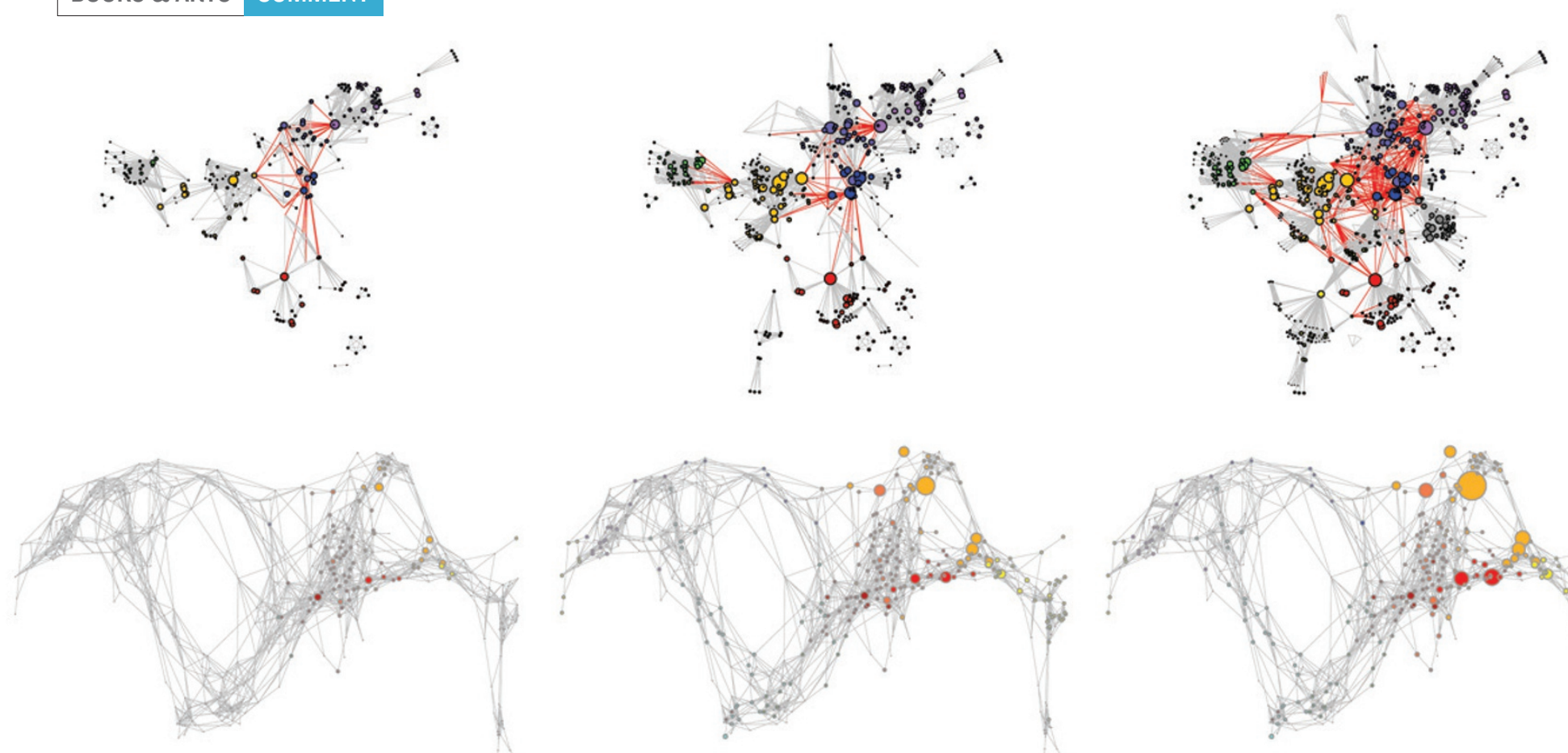

A visualization maps the impact of US National Institutes of Health funding strategies on authorship networks (top) and publication output (bottom).

\title{
DATA VISUALIZATION
}

Mapping the topical space

\section{Rikke Schmidt Kjærgaard applauds a cogent guide to scientific cartography.}

$\mathrm{F}$ lip through ten pages of this issue of Nature, and your eyes will be drawn to headlines and images. In our information-thick, data-supported world, optimal representation is key. Yet many scientists lack the tools and training to create great data visualization - to digitally parse data in many dimensions, revealing patterns and relationships in phenomena ranging from patent citations to the evolution of great scientific discoveries.

Guidance is on offer from books such as Edward Tufte's Envisioning Information (Graphics Press, 1990) and Stephen Few's Show Me the Numbers (Analytics Press, 2004). In recent years, Nature Methods' Points of View column by Bang Wong, Martin Kryzwinski and invited co-authors has tested design rules on real data sets (see go.nature.com/3scjfr). Now, in Atlas of Knowledge, information scientist Katy Börner aims to bring much of this together. As the second book in a series of three, it follows Atlas of Science (MIT Press, 2010), an introduction to the power of information visualization (see B. Schneiderman Nature 468, 1037; 2010). Both books complement Börner's comprehensive travelling exhibition Places \& Spaces: Mapping Science, now in its tenth year (http://scimaps.org).

In Atlas of Knowledge, Börner gives guidance on how to 'map' - make visualizations of statistical, temporal, geospatial, topical and network data to aid intelligent decision-making by scientists, economists and policy-makers. One standout example is the beautiful 2011 'Design vs Emergence: Visualization of Knowledge Orders' by Alkim Almila Akdag Salah and her colleagues, which compares Wikipedia's category structure with the Universal Decimal Classification system. The book as a whole is an impressive, visually captivating resource, although ultimately it is more a tour inviting comparison and inspiration than a step-by-step manual.

In part 1, Börner first explores research at the micro level, such as the evaluation of individual scholarly merit on the basis of citation counts, prestige, internationalization and funding. She progresses by stages to multilevel and universal research, including investigating population size, life expectancy, national debts and gross domestic product on a global scale. Part 2 introduces valuable techniques for general data analysis and visualization, including how to

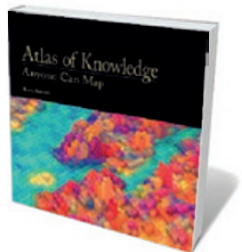

Atlas of Knowledge: Anyone Can Map KATY BÖRNER MIT Press: 2015 map geospatial location, correlations and $\stackrel{o}{z}$ relationships, trends and distribution. Börner presents an encyclopaedia of examples of needs-driven workflow design and data scale, 空 as well as types of visualization such as tables, charts, graphs, maps and networks.

The practical value of the book lies in bringing these case studies together to evaluate the pros and cons of different strategies in visualization design. The variety is breathtaking. An example of Hans Rosling's Gapminder visualizations, for instance, lays out global socioeconomic data for 1930-2012; derived from Rosling's graph Wealth \& Health of Nations, it was crafted with the Trendalyzer software that he developed for animating statistics. And Ben Fry's 'On the Origin of Species: The Preservation of Favoured Traces' (http:// benfry.com/traces/) compares editions of Darwin's magnum opus using Processing, an open-source programming language used to teach computational design. Both pack comprehensive data into easy-to-read graphics, utilizing variables such as colour, geometry, statistics and development over time.

Part 3 is where Atlas of Knowledge stands out from other treatments, presenting 40 full-page iconic images authored by pioneers of data visualization. The visionary US architect Buckminster Fuller, for instance, was - with artist and sociologist 

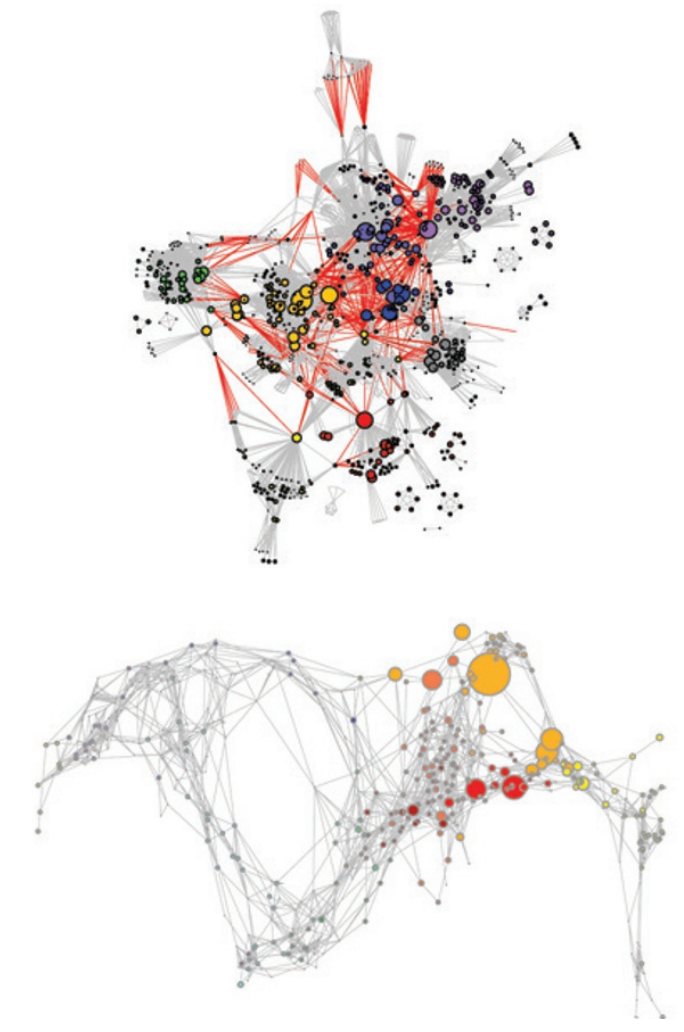

John McHale - one of the first to chart long-term trends of industrialization and globalization. The 1965 chart 'Shrinking of Our Planet by Man's Increased Travel and Communication Speeds Around the Globe' maps how the confluence of communication and transportation technologies from 500,000 BC to 1965 have conquered distance.

However, you will need to go to the Places \& Spaces website to fully appreciate the complexity and interactivity of many of the twenty-first-century digital visualizations. For example, in print it is hard to locate the bacterium Streptococcus pneumoniae on the 2006 'Tree of Life' map by Peer Bork and his colleagues, which shows 191 species with fully sequenced genomes. Moreover, the wealth of examples and illustrations in Börner's book is sometimes a bit too rich. With fewer images, it would have been possible to lead readers into the details, allowing us to see what is at stake without running back and forth between book and screen.

Atlas of Knowledge places itself in a long line of resources on data visualization. The focus is less on how-to than it was in, say, Felice Frankel and Angela DePace's Visual Strategies (Yale Univ. Press, 2012), but Börner's book has a place on my shelf. Whether you read it cover to cover or just browse the extraordinary examples, you put it down inspired.

Rikke Schmidt Kjærgaard is associate professor of scientific data visualization and head of the Visualization Lab at Aarhus Institute of Advanced Studies, Aarhus University, Denmark. e-mail:risk@aias.au.dk

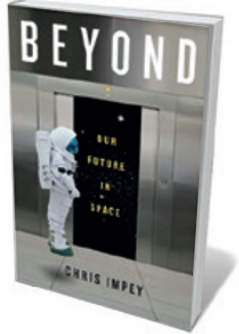

Beyond: Our Future in Space

Chris Impey W. W. NORTON (2015)

Does navigating a pure vacuum while "strapped to a barely controlled chemical explosion" appeal? Yes — to a select proportion of us, notes astronomer Chris Impey in this bold, elegant and engaging exploration of space travel past, present and future. Impey ranges widely, over a variant of the dopamine-controlling gene DRD4 that may encourage astronauts to seek novelty; the work of visionaries such as rocket scientist Konstantin Tsiolkovsky; the trajectories of national space programmes; advances in robotics and exoplanet discoveries; the potential for extraterrestrial life; and far beyond.

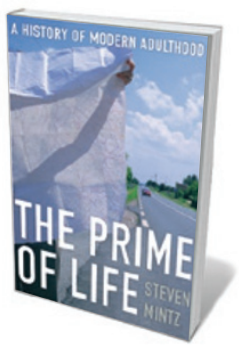

The Prime of Life: A History of Modern Adulthood

Steven Mintz BELKNAP (2015)

Coming of age, argues historian Steven Mintz, is not what it used to be. Characterizing adulthood as a "historical black hole", Mintz sets out to trace the concept's trajectory from the nineteenth century to its 1950s apex, and its disintegration in our individualistic times. He looks at shifts in intimacy, marriage, parenthood and work, noting that some $80 \%$ of today's US citizens in their late twenties have yet to tick off all the traditional indicators of adulthood, such as leaving home. Yet we need to dig deeper to redefine adulthood, he avers - not least, by reinstating qualities such as judgement to the definition.

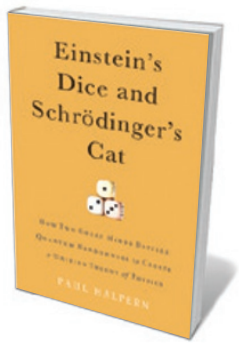

Einstein's Dice and Schrödinger's Cat: How Two Great Minds Battled Quantum Randomness to Create a Unified Theory of Physics Paul Halpern BASIC (2015)

Physicist Paul Halpern tells the entangled tale of Albert Einstein, Erwin Schrödinger and their search for a Grand Unified Theory with humour and concision. Schrödinger allied himself with Einstein to counter the orthodox quantum view championed by Niels Bohr and others. But as Halpern reminds, Schrödinger was as contradictory as his famous thought experiment, and Einstein was prone to premature announcements of theoretical success. A spat between them, he shows, deprived them of further collaboration, and us of the fruits.

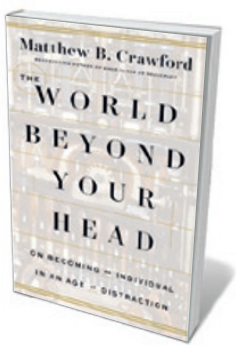

The World Beyond Your Head: On Becoming an Individual in an Age of Distraction

Matthew B. Crawford FarRar, Straus AND GIROUX (2015)

In this follow-up to his Shop Class as Soulcraft (Penguin, 2009), philosopher-mechanic Matthew Crawford looks at the toll that the assault of constant advertisements, mobile-phone calls and more are having on our collective psyche. The resulting fragmentation and dissociation are well documented. Crawford's solutions creating an "ethics of attention" and reclaiming "the real" through, for instance, craft - are pragmatic, but the rather belaboured philosophical overlay sometimes wars with his message.

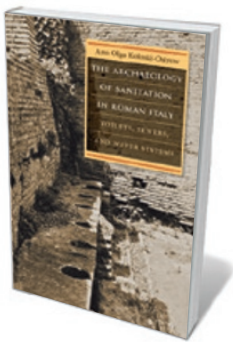

The Archaeology of Sanitation in Roman Italy: Toilets, Sewers, and Water Systems

Ann Olga Koloski-Ostrow UnIV. NORTH CAROLINA PRESS (2015)

From aqueducts to amphitheatres, ancient Rome was a hotbed of engineering. That ingenuity percolated downwards too, as classicist Ann Olga Koloski-Ostrow shows in this uneven yet enlightening treatise on sanitation in Roman Italy in the first centuries BC and AD. Homing in on Herculaneum, Ostia, Pompeii and Rome, she explores sanitation design, concepts of hygiene and the role of scatology in the literature and public-toilet graffiti of the time. Barbara Kiser 